\title{
Cardiovascular Regenerative Technologies: Update and Future Outlook
}

\author{
Anna Mallone Benedikt Weber Simon P. Hoerstrup \\ Institute for Regenerative Medicine, University of Zurich, Schlieren, Switzerland
}

\section{Keywords}

Regenerative medicine - Cell therapy .

Tissue engineering - Cardiovascular disease .

Ischemic heart disease - Heart valve disease

\section{Summary}

In the effort of improving treatment for cardiovascular disease (CVD), scientists struggle with the lack of the regenerative capacities of finally differentiated cardiovascular tissues. In this context, the advancements in regenerative medicine contributed to the development of cellbased therapies as well as macro- and micro-scale tissue-engineering technologies. The current experimental approaches focus on different regenerative strategies including a broad spectrum of techniques such as paracrine-based stimulation of autologous cardiac stem cells, mesenchymal cell injections, 3D microtissue culture techniques and vascular tissue-engineering methods. These potential next-generation strategies are leading the way to a revolution in addressing CVD, and numerous studies are now undertaken to assess their therapeutic value. With this review, we provide an update on the current research directions, on their major challenges, limitations, and achievements.

(c) 2016 S. Karger GmbH, Freiburg

\section{Introduction}

Cardiovascular disease (CVD) includes a plethora of disorders affecting the cardiovascular system comprising, among others, heart failure (HF) and heart valve disease (HVD). Frequently, HF is caused by coronary artery occlusion and can lead to acute ischemic episodes (ischemic heart disease; IHD). Due to poor or absent postischemic reperfusion of the infarcted myocardial areas, a significant amount of cardiomyocytes undergoes apoptosis and is replaced by fibrous scar tissue. The relative unpredictability of acute cardiovascular events, the high mortality rate and the absence of a durable post-ischemic treatment, endorse IHD to one of the most critical clinical hurdle of this century. The long-term survival of patients with heart failure is compromised by a series of complications as the massive proliferation of non-contractile fibrotic tissue in the infarcted areas. Additionally, after acute ischemic episodes, patients endure life-changing treatments ranging from daily medications to surgical interventions, e.g., pacemakers, stents, angioplasty or heart transplants. In this context, regenerative medicine can be considered as innovative and valid alternative. The identification of progenitor cardiac cells within the adult human heart [1] encouraged the enthusiasm for cell-based regenerative therapies [2-4]. Moreover, the evidence that exogenous cells injected in the myocardium could minimally promote the formation of functional contractile tissue in the scarred areas provided an important contribution in directing the preclinical research towards the investigation of possible new treatments [5].Together with IHD, HVD represents a leading cause of mortality worldwide [6]. Different valve pathologies are grouped under the HVD acronym, e.g., valve stenosis or prolapse; the latter are mainly caused by congenital heart valve defects, infections or age-related pathological changes. New techniques and prostheses for valve replacement have been introduced into clinical routine, increasing the range of treatment opportunities for the patients. Despite these efforts, today's heart valve artificial prostheses are still associated with increasing risk of thrombogenic events, progressive degeneration, and calcification. In this scenario, regenerative medicine technologies such as tissue engineering hold the potential to overcome the wide range of harmful limitations. The concept of heart valve tissue engineering encompasses the isolation, expansion, and seeding of patient-derived cells onto biodegradable scaffolds; this process is followed by in vitro culture and subsequent in vivo implantation of the final construct into the patient. The resulting bioengineered valve can potentially provide non-immunogenic, non-thrombogenic characteristics together with growth and remodeling properties. The research in the

\section{KARGER}

Fax +497614520714

\section{(ㄷ) 2016 S. Karger GmbH, Freiburg}

$1660-3796 / 16 / 0434-0291 \$ 39.50 / 0$

Accessible online at:

www.karger.com/tmh
Anna Malone

Institute for Regenerative Medicine

University of Zurich

Wagistrasse 12, 8952 Schlieren, Switzerland

anna.mallone@bli.uzh.ch 
field is now focusing on new cell sources and new biomaterials; the optimal combination of these two factors could indeed contribute in raising the versatility and extending the horizons of the field of heart valve tissue engineering.

\section{Regenerative Technologies for Heart Failure}

Despite the recent advances of basic research in the field, the detailed architecture of cardiac repair response upon ischemia is currently not clear. The presence of progenitor cells capable of a local and limited regenerative activity in the adult heart inspired the study and development of both i) cell-based technologies and ii) strategies for paracrine stimulation of the resident cardiac progenitor cells. The next paragraphs will introduce and discuss both regenerative approaches.

\section{Cell-Based Regenerative Technologies: From Single Cell to Bioengineered Microtissues}

Over the past decades preclinical and clinical investigations of cell-based technologies for the treatment of the infarcted heart have been carried out. Different cell candidates were evaluated in vitro and are now under investigation for a possible therapeutic use. Examples are autologous in vitro-expanded cardiac progenitor cells (CPCs) and autologous adipose tissue- or bone marrow-derived mesenchymal stem cells (MSCs) [7]. Although clinical trials based on the intra-myocardial injection of single-cell suspensions have been performed with mesenchymal autologous cells, the interpretation of the results is controversial and roused questions and doubts regarding the power of the technology [8-10]. There is currently a consensus regarding the possible reasons for the singlecell suspension therapy failure; the negative results are addressed to the scarce survival and retention of the cells at the level of the infarcted area [11]. The newest regenerative approaches aim at enhancing survival, grafting, and retention abilities of the injected cells using different methodologies. An example is provided by the cutting-edge bioengineered microtissue technology. Microtissues are scaffold-free tissue-engineered spheroids generated via hanging drop technique. These microstructures are reproducible with different cell types like CPCs, bone marrow- and adipose tissue-derived MSCs [4] and have been tested in a pilot study on infarcted porcine models exhibiting promising results [12]. Other methods currently investigated for increasing cell retention in the infarcted areas include i) the combination of single cell suspensions with nanoparticles loaded with functional agents [13], ii) the injection of a compact mixture of cells pre-cultured in hydrogels [14], or iii) the injection of cell-free hydrogels functionalized with paracrine mediators [15].

\section{Paracrine Stimulation of Resident Progenitor Cells}

The self-regenerative ability of the adult heart is per se inefficient to stimulate the functional replacement of necrotic areas and prevent the formation of fibrous tissue after myocardial infarction. Regenerative mechanisms demand tailored triggers that are pro- vided by cell-cell communication. It is known that epicardium and endocardium share a communication network based on vesicular exchange [16]; cells can indeed exchange information by packing and delivering ribonucleic acids and proteins within microvesicles known as exosomes (EVs) [17-19]. A branch of recently developed regenerative technologies adopted this mechanism of cell-cell communication to stimulate and increase the physiological regenerative processes upon injury. The vesicular content of EVs varies according to environmental clues (i.e., hypoxic conditions or acute myocardial infarction) and provides growth factors, anti-apoptotic and angiogenic as well as mitogenic signals. In detail, EVs are predominantly enriched in microRNAs (miRNA), small noncoding RNA molecules with the function of post-transcriptional regulators [20]. Cardiomyocyte-specific extracellular factors and miRNAs (e.g. miR-1, miR-133, and miR-206) are key regulators of cardiac function and are released in high concentrations upon heart injury, exerting their regulatory role on the surrounding cells $[21,22]$. The beneficial and synergic function of specific combinations of miRNAs on CPCs has been proven together with the hypothesis that miRNA families can selectively be secreted into the extracellular environment via exosomes $[23,24]$. The recent EVinspired regenerative technologies focus either on i) the drug-exerted stimulation of cardiac progenitors $[25,26]$ or ii) the in situ miRNA-targeted delivery [27]. Different studies contributed to the development of these technologies, like the in vitro and in vivo investigation of the secretome and extracellular vesicular content of MSCs. These studies led to the discovery of new cardioprotective molecules [28-31]. In this regard, Timmers et al. [30] showed in 2007 the beneficial effects of MSC-conditioned medium upon injection in a pig model of ischemia/reperfusion, reporting a significant reduction in the ischemic myocardial area after the treatment. More recently, the secretome of human amniotic membrane-derived MSCs was injected in infarcted rat models, leading to a reduction of the ischemic area and ventricular remodeling [28]. Although these promising studies are still at the preclinical level, they have the potential to shorten the distance from clinical trials to a possible therapeutic approach in humans [32].

\section{Regenerative Technologies for Heart Valve Disease}

The landscape of medical treatments for valvular disease is in constant expansion, providing hope in the possibility of improving HVD patients' life expectancies. The most investigated and performed treatment for late-stage valvular dysfunctions is, at the moment, heart valve replacement [6]. Different types of for valvular substitutes are available but the best option must be chosen considering different key parameters such as thromboresistance, implantability, hemodynamics, and durability of the substitute device. The constant search for a durable, safe alternative for heart valve replacement stimulated a rapid development in the field of tissue engineering. The bioengineered constructs are indeed autologous and potentially able to grow and adapt to the changing organ anatomy of a child, avoiding the hurdle of iterated surgery (fig. 1) [33, 34]. 
Fig. 1. Overview of the tissue engineering approach and scaffold matrices. Cells are seeded on support matrix shaped like a trileaflet heart valve. In the figure peculiar scaffold materials for tissue engineering are summarized and include i) synthetic matrices, ii) biological matrices, and iii) decellularized tissues. The final goal is the production of a tissue engineered heart valve (TEHV) characterized by optimal durability, thromboresis tance, and hemodynamic profile.
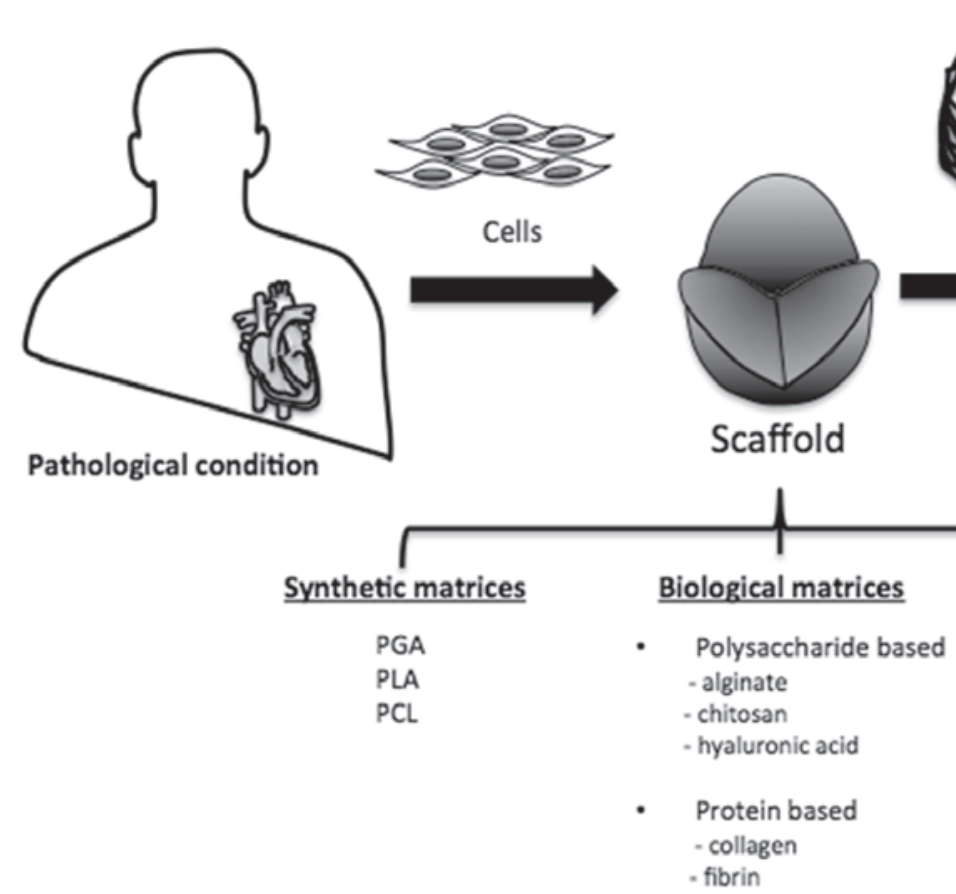

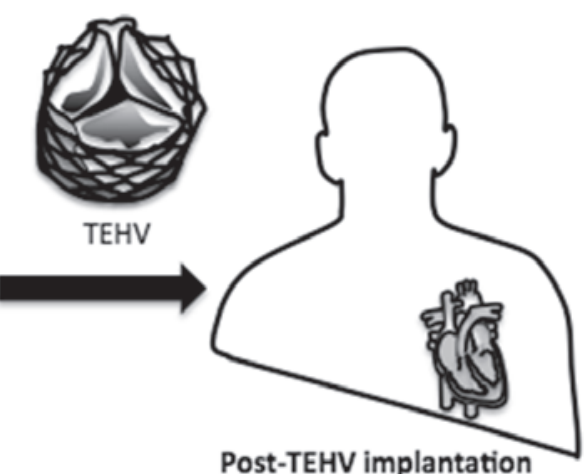

Decellularized tissues

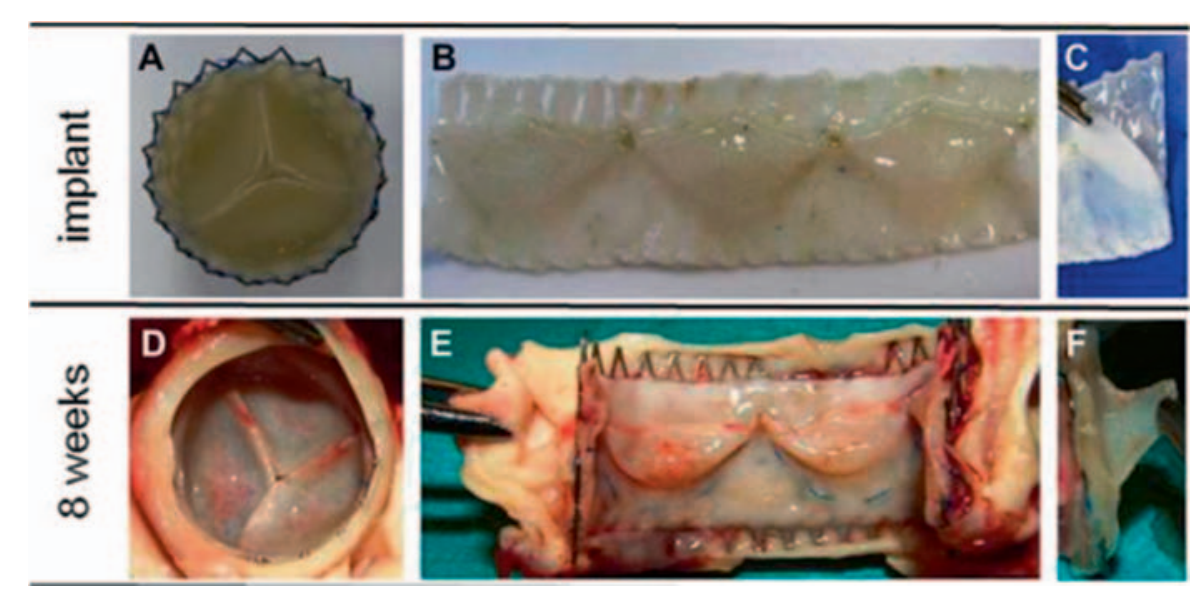

Fig. 2. Macroscopic appearance of decellularized in vitro grown tissue engineered heart valve. Adapted from Driessen et al. 2014 [34]. Macroscopic appearance of an implanted (A-C) and explanted (D-F) decellularized in vitro grown heart valve in closed configuration $(\mathbf{A}, \mathbf{D})$, opened configuration $(\mathbf{B}, \mathbf{E})$, and as cross section $(\mathbf{C}, \mathbf{F})$.

Tissue Engineering Technologies for Heart Valve Replacement

Tissue engineering approaches are largely investigated in the field cardiovascular medicine and mainly rely on the fabrication of tissue-engineered blood vessels and heart valves. The key steps in today's heart valve in vitro fabrication start with the isolation of cells from the patient. Cells are then expanded, characterized, and seeded onto biodegradable molds (fig. 1). Due to extracellular matrix (ECM) production and concomitant scaffold degradation, the bioengineered heart valve is shaped and in vitro manufactured; potentially ready to be implanted [35-37]. Advanced tissue engineering approaches are based on dynamic, pulsatile flow culturing strategies. These are fulfilled using in vitro bioreactor systems to simulate physiological mechanical stimuli provided by blood pressure and flow [38]. Recently, a second, promising regenerative technology, known as in situ tissue engineering, has been investigated. The latter is based on the hypothesis that the most appropriate scaffold for tissue engineering is the ECM itself. According to this hypothesis, spontaneous scaffold-driven endogenous cell re- cruitment and migration may occur in situ, leading to a complete ECM scaffold repopulation. To achieve this goal, native matrices are obtained through tissue decellularization and tested for in situ tissue engineering (fig. 2) [34, 39-41].

\section{Biomaterials for Heart Valve Tissue Engineering}

The chemical composition of the scaffold matrices employed for tissue engineering is crucial for the success of the valvular fabrication process. The predominant scaffolding approach is based on the use of pore networks of biodegradable scaffolds [37, 42]. These porous networks are important for nutrient supply and are the common standard for the design of new biomaterials because they guarantee high reproducibility and low costs as well as remarkable mechanical strength and predictable physical properties. Many studies have investigated various fabrication techniques in order to generate novel structures for tissue engineering applications, e.g. polymers assembled with various electrospun designs [43-46]. Today's attempts in developing scaffolds for tissue engineering are 
proceeding in two directions and are based on the use of more or less complex polymers from different sources that are either i) fully synthetic or based on ii) biological matrices. A huge variety of biodegradable synthetic polymers have been synthesized and historically proposed as suitable tissue engineering matrices [47], for example, polyglycolic acid (PGA), polylactic acid (PLA), poly-4-hydroxybutyrate $(\mathrm{P} 4 \mathrm{HB})$ and polycaprolactone $(\mathrm{PCL})$ all suitable for tissue engineering, being biodegradable and varying in manufacturing shapes (fig. 1). Among these, aliphatic polyester composite structures are considered as one of the best choices for tissue engineering. One of their main features of interest resides in their relative resistance to fast hydrolytic degradation, which is a discriminatory point given the obliged culture in aqueous media [48]. Their erosive degradation starts from the ester bonds in their polymeric backbone and is continued by random hydrolysis and concomitant enzymatic esterase activity $[49,50]$ while the degradation products are bio-resorbed in the common cellular metabolic pathways. The scaffold produced using biological matrices can be used alone or in combination with synthetic polymers [51]. The large class of bioscaffolds includes, among the others, polysaccharides such as alginate and proteins such as collagen and fibrin [52]. These biomaterials were the subject of a recent revolution starting with the advent of 3D-bioprinting techniques. In 2013 Duan et al. [53] performed 3D-bioprint living alginate/gelatin hydrogel aortic valves, incorporating within the biomaterial both smooth muscle cells and aortic valve leaflet interstitial cells, the main cell populations in the valve leaflets. However, despite the initial success of the biomatrices, the synthetic materials are still considered a better choice for tissue engineering due to their high durability. Of great interest among biomaterials used for heart valve tissue engineering are the commercially produced polyhydroxylalkanoates, microbial polyesters that can be manufactured with the desired length and degradation time [54]. This family includes polymers such as poly-4-hydroxybutyrate $(\mathrm{P} 4 \mathrm{HB})$ generally combined with other synthetic polymers (e.g. PGA) for the final manufacture of a hybrid scaffold. PGA$\mathrm{P} 4 \mathrm{HB}$ is the today's most used combination for the production of tri-leaflet heart valves due to the successful coupling of materialrelated biophysical characteristics, joining the high porosity of PGA with the thermoplasticity of P4HB. The decellularized tissuederived matrices conclude the excursus on biomaterials for heart valve regenerative technologies. The possibility to use tissue-derived templates made of naturally assembled networks of ECM is inevitably interesting as an alternative to the materials described above. One of the main unsolved questions is the matter of the donor source. The latter has to be properly chosen to avoid a possible immune response in the host or disease transmission [55]. Therefore, the choice of the donor tissue must be accurate; today's most used decellularized scaffold matrices are derived from homografts or xenografts [56]. A recent study investigated the repopulation capacity of decellularized tissue-engineered heart valves in a non-human primate model up to 8 weeks [39], showing a rapid cellular repopulation of the decellularized constructs and high remodeling capacities. This study underlines the strong translational power of this technology.

\section{Cell Sources for Heart Valve Tissue Engineering}

Other crucial variables to be considered for a fruitful in vitro tissue-engineered valvular production include i) the cell type used for the seeding onto the valvular molds, ii) the culture type, meaning either single cell type cultures or co-culture systems, and iii) ECM production coupled with biomaterial degradation rates [57]. Additionally, cells should be of autologous origin, non-immunogenic, and possessing pronounced plasticity. A wide panel of cell types with such characteristics has been investigated for tissue engineering, like vascular tissue, adipose tissue, umbilical cord blood, chorionic villi, amniotic fluid-derived cells, or cells directly differentiated from patients' induced pluripotent stem cells (iPSCs). Cells derived from vascular tissues (e.g. from peripheral arteries or umbilical veins) are so far the cell types preferred for scaffold seeding for tissue engineered heart valve production [6]. Usually, two main cell populations are isolated from this tissue type: endothelial cells and myofibroblasts. The latter are responsible for the creation of a stable environment for the endothelial cells by depositing ECM, while endothelial cells generate a tight and confluent layer $[33,40]$. Stem cells are one of today's most interesting options for tissue engineered valve production [37] due to their fast growth and extensive potential to differentiate towards different cell fates. Among them, MSCs not only share important phenotypic traits with the valve interstitial cells but also retain a great cellular potency and can be isolated with minimally invasive interventions. This endorses MSCs as one of the most suitable stem cell candidates for valvular bioengineering. In recent years, another interesting cell source has become available. In 2006 Yamanaka et al. [58] managed to reprogram adult fibroblasts to a pluripotent status, obtaining iPSCs. Due to their non-embryonic origin, the use of iPSCs for tissue engineering could potentially overcome all ethical problems, allowing to create a patientspecific valvular construct by differentiating the stem cells generated from autologous skin biopsy [59].

\section{Conclusions}

The present review summarizes the most recent regenerative technologies developed for the treatment of CVD. In particular, it provides an overview of the regenerative strategies in the context of IHD and HVD. It is possible to identify few promising concepts that are drawing the future of the field. One of them is the idea of replacing/combining stem cell-based therapies for the infarcted heart with an intra-myocardial injection of a cardioprotective cocktail. Other intriguing concepts are i) the use of microtissues as a possible alternative to cell therapy performed with single-cell suspensions and ii) the heart valve tissue engineering technology. The first is considered a promising cell delivery system for enhancing cellular engraftment and survival in the infarcted myocardium; the second aims at revolutionizing the field of heart valve replacement with the use of decellularized tissues for promoting in situ tissue regeneration. 


\section{Disclosure Statement}

The authors have not conflicts of interest to report.

\section{References}

1 Beltrami AP, Barlucchi L, Torella D, Baker M, Limana F, Chimenti S, Kasahara H, Rota M, Musso E, Urbanek K, Leri A, Kajstura J, Nadal-Ginard B, Anversa P: Adult cardiac stem cells are multipotent and support myocardial regeneration. Cell 2003;114:763-776.

2 Menasche P, Hagege AA, Scorsin M, Pouzet B, Desnos M, Duboc D, Schwartz K, Vilquin JT, Marolleau JP: Myoblast transplantation for heart failure; Lancet 2001;357:279-280.

3 Boyle AJ, Schulman SP, Hare JM, Oettgen P: Is stem cell therapy ready for patients? Stem cell therapy for cardiac repair. Ready for the next step. Circulation 2006;114:339-352.

4 Emmert MY, Wolint P, Wickboldt N, Gemayel G Weber B, Brokopp CE, Boni A, Falk V, Bosman A, Jaconi ME, Hoerstrup SP: Human stem cell-based three-dimensional microtissues for advanced cardiac cell therapies. Biomaterials 2013;34:6339-6354.

5 Behfar A, Crespo-Diaz R, Terzic A, Gersh BJ: Cell therapy for cardiac repair - lessons from clinical trials. Nat Rev Cardiol 2014;11:232-246.

6 Emmert MY, Weber B, Falk V, Hoerstrup SP: Transcatheter tissue engineered heart valves. Expert Rev Med Devices 2014;11:15-21.

7 Forte E, Chimenti I, Barile L, Gaetani R, Angelini F, Ionta $\mathrm{V}$, Messina $\mathrm{E}$, Giacomello A: Cardiac cell therapy: the next (re)generation. Stem Cell Rev 2011;7: 1018-1030.

8 Stamm C, Westphal B, Kleine HD, Petzsch M, Kittner C, Klinge H, Schumichen C, Nienaber CA, Freund M, Steinhoff G: Autologous bone-marrow stem-cell transplantation for myocardial regeneration. Lancet 2003; 361:45-46.

9 Lunde K, Solheim S, Aakhus S, Arnesen H, Abdelnoor M, Egeland T, Endresen K, Ilebekk A, Mangschau A, Fjeld JG, Smith HJ, Taraldsrud E, Grogaard HK, Bjornerheim R, Brekke M, Muller C, Hopp E, Ragnarsson A, Brinchmann JE, Forfang K: Intracoronary injection of mononuclear bone marrow cells in acute myocardial infarction. N Engl J Med 2006;355:1199-1209.

10 Rota M, Leri A, Anversa P: Human heart failure: is cell therapy a valid option? Biochem Pharmacol 2014;88: 129-138.

11 Abdelwahid E, Kalvelyte A, Stulpinas A, de Carvalho KA, Guarita-Souza LC, Foldes G: Stem cell death and survival in heart regeneration and repair. Apoptosis 2016;21:252-268.

12 Emmert MY, Wolint P, Winklhofer S, Stolzmann P, Cesarovic N, Fleischmann T, Nguyen TD, Frauenfelder T, Boni R, Scherman J, Bettex D, Grunenfelder J, Schwartlander R, Vogel V, Gyongyosi M, Alkadhi H, Falk V, Hoerstrup SP: Transcatheter based electromechanical mapping guided intramyocardial transplantation and in vivo tracking of human stem cell based three dimensional microtissues in the porcine heart. Biomaterials 2013;34:2428-2441.

13 Zhu K, Li J, Wang Y, Lai H, Wang C: Nanoparticlesassisted stem cell therapy for ischemic heart disease. Stem Cells Int 2016;2016:1384658.

14 Sepantafar M, Maheronnaghsh R, Mohammadi H, Rajabi-Zeleti S, Annabi N, Aghdami N, Baharvand H: Stem cells and injectable hydrogels: synergistic therapeutics in myocardial repair. Biotechnol Adv 2016;34: 362-379.
15 Hasan A, Waters R, Roula B, Dana R, Yara S, Alexandre T, Paul A: Engineered biomaterials to enhance stem cell-based cardiac tissue engineering and therapy. Macromol Biosci 2016; doi: 10.1002/mabi.201500396.

16 Kishore R, Khan M: More than tiny sacks: stem cell exosomes as cell-free modality for cardiac repair. Circ Res 2016;118:330-343.

17 Yuan MJ, Maghsoudi T, Wang T: Exosomes mediate the intercellular communication after myocardial infarction. Int J Med Sci 2016;13:113-116.

18 Sahoo S, Losordo DW: Exosomes and cardiac repair after myocardial infarction. Circ Res 2014;114:333344.

19 Chistiakov DA, Orekhov AN, Bobryshev YV: Cardiac extracellular vesicles in normal and infarcted heart. Int J Mol Sci 2016;17:E63.

20 Valadi H, Ekstrom K, Bossios A, Sjostrand M, Lee JJ, Lotvall JO: Exosome-mediated transfer of mrnas and micrornas is a novel mechanism of genetic exchange between cells. Nat Cell Biol 2007;9:654-659.

21 Khanabdali R, Rosdah AA, Dusting GJ, Lim SY: Harnessing the secretome of cardiac stem cells as therapy for ischemic heart disease; Biochem Pharmacol 2016; doi: 10.1016/j.bcp.2016.02.012.

22 Mitchelson KR, Qin WY: Roles of the canonical myomirs mir-1,-133 and -206 in cell development and disease. World J Biol Chem 2015;6:162-208.

23 Pisano F, Altomare C, Cervio E, Barile L, Rocchetti M, Ciuffreda MC, Malpasso G, Copes F, Mura M, Danieli P, Viarengo G, Zaza A, Gnecchi M: Combination of miRNA499 and miRNA133 exerts a synergic effect on cardiac differentiation. Stem Cells 2015;33:1187-1199.

24 Ohshima K, Inoue K, Fujiwara A, Hatakeyama K, Kanto K, Watanabe Y, Muramatsu K, Fukuda Y, Ogura S, Yamaguchi K, Mochizuki T: Let-7 microRNA family is selectively secreted into the extracellular environment via exosomes in a metastatic gastric cancer cell line. PLoS One 2010;5:e13247.

25 Park A, Barrera-Ramirez J, Ranasinghe I, Pilon S, Sy R, Fergusson D, Allan DS: Use of statins to augment progenitor cell function in preclinical and clinical studies of regenerative therapy: a systematic review. Stem Cell Rev 2016;12:327-339.

26 Broughton KM, Sussman MA: Empowering adult stem cells for myocardial regeneration v2.0: success in small steps. Circ Res 2016;118:867-880.

27 Kamps JA, Krenning G: Micromanaging cardiac regeneration: Targeted delivery of microRNAs for cardiac repair and regeneration. World J Cardiol 2016;8: 163-179.

28 Danieli P, Malpasso G, Ciuffreda MC, Cervio E, Calvillo L, Copes F, Pisano F, Mura M, Kleijn L, de Boer RA, Viarengo G, Rosti V, Spinillo A, Roccio M, Gnecchi M: Conditioned medium from human amniotic mesenchymal stromal cells limits infarct size and enhances angiogenesis. Stem Cells Transl Med 2015;4: $448-458$.

29 Arslan F, Lai RC, Smeets MB, Akeroyd L, Choo A, Aguor EN, Timmers L, van Rijen HV, Doevendans PA, Pasterkamp G, Lim SK, de Kleijn DP: Mesenchymal stem cell-derived exosomes increase ATP levels, decrease oxidative stress and activate PI3K/Akt pathway to enhance myocardial viability and prevent adverse remodeling after myocardial ischemia/reperfusion injury. Stem Cell Res 2013;10:301-312.
30 Timmers L, Lim SK, Hoefer IE, Arslan F, Lai RC, van Oorschot AA, Goumans MJ, Strijder C, Sze SK, Choo A, Piek JJ, Doevendans PA, Pasterkamp G, de Kleijn DP: Human mesenchymal stem cell-conditioned medium improves cardiac function following myocardial infarction. Stem Cell Res 2011;6:206-214.

31 Yamaguchi S, Shibata R, Yamamoto N, Nishikawa M, Hibi H, Tanigawa T, Ueda M, Murohara T, Yamamoto A: Dental pulp-derived stem cell conditioned medium reduces cardiac injury following ischemia-reperfusion. Sci Rep 2015;5:16295.

32 Akyurekli C, Le Y, Richardson RB, Fergusson D, Tay J, Allan DS: A systematic review of preclinical studies on the therapeutic potential of mesenchymal stromal cellderived microvesicles. Stem Cell Rev 2015;11:150-160.

33 Hoerstrup SP, Weber B: Biological heart valves. Eur Heart J 2015;36:325-326.

34 Driessen-Mol A, Emmert MY, Dijkman PE, Frese L, Sanders B, Weber B, Cesarovic N, Sidler M, Leenders J, Jenni R, Grunenfelder J, Falk V, Baaijens FP, Hoerstrup SP: Transcatheter implantation of homologous 'Off-the-shelf tissue-engineered heart valves with selfrepair capacity: long-term functionality and rapid in vivo remodeling in sheep. J Am Coll Cardiol 2014;63: 1320-1329.

35 Schoen FJ: Evolving concepts of cardiac valve dynamics: the continuum of development, functional structure, pathobiology, and tissue engineering. Circulation 2008;118:1864-1880.

36 Schmidt D, Stock UA, Hoerstrup SP: Tissue engineering of heart valves using decellularized xenogeneic or polymeric starter matrices. Philos Trans R Soc Lond B Biol Sci 2007;362:1505-1512.

37 Namiri M, Ashtiani MK, Mashinchian O, Hasani-Sadrabadi MM, Mahmoudi M, Aghdami N, Baharvand $\mathrm{H}$ : Engineering natural heart valves: possibilities and challenges. J Tissue Eng Regen Med 2016

38 Parvin Nejad S, Blaser MC, Santerre JP, Caldarone CA, Simmons CA: Biomechanical conditioning of tissue engineered heart valves: too much of a good thing?; Adv Drug Deliv Rev 2016;96:161-175.

39 Weber B, Dijkman PE, Scherman J, Sanders B, Emmert MY, Grunenfelder J, Verbeek R, Bracher M, Black M, Franz T, Kortsmit J, Modregger P, Peter S, Stampanoni M, Robert J, Kehl D, van Doeselaar M, Schweiger M, Brokopp CE, Walchli T, Falk V, Zilla P, Driessen-Mol A, Baaijens FP, Hoerstrup SP: Off-the-shelf human decellularized tissue-engineered heart valves in a non-human primate model. Biomaterials 2013;34:7269-7280.

40 Weber B, Hoerstrup SP: The future of heart valve replacement. Eur Heart J 2015;36:326-328

41 Roosens A, Somers P, De Somer F, Carriel V, Van Nooten G, Cornelissen R: Impact of detergent-based decellularization methods on porcine tissues for heart valve engineering. Ann Biomed Eng 2016; DOI: 10.1007/s10439-016-1555-0.

42 Chan BP, Leong KW: Scaffolding in tissue engineering: general approaches and tissue-specific considerations. Eur Spine J 2008;17(suppl 4):467-479.

43 Schaefermeier PK, Szymanski D, Weiss F, Fu P, Lueth T, Schmitz C, Meiser BM, Reichart B, Sodian R: Design and fabrication of three-dimensional scaffolds for tissue engineering of human heart valves. Eur Surg Res 2009;42:49-53. 
44 Freeman R, Boekhoven J, Dickerson MB, Naik RR, Stupp SI: Biopolymers and supramolecular polymers as biomaterials for biomedical applications. MRS Bull 2015;40:1089-1101.

45 Li YF, Gregersen H, Nygaard JV, Cheng W, Yu Y, Huang Y, Dong M, Besenbacher F, Chen M: Ultraporous nanofeatured PCL-PEO microfibrous scaffolds enhance cell infiltration, colonization and myofibroblastic differentiation. Nanoscale 2015;7:14989-14995

46 Stefani I, Cooper-White JJ: Development of an in-process UV-crosslinked, electrospun PCL/aPLA-co-TMC composite polymer for tubular tissue engineering applications. Acta Biomater 2016;36:231-440

47 Sodian R, Hoerstrup SP, Sperling JS, Daebritz S, Martin DP, Moran AM, Kim BS, Schoen FJ, Vacanti JP, Mayer JE Jr: Early in vivo experience with tissue-engineered trileaflet heart valves. Circulation 2000;102 Iii22-29.

48 Vert M: Aliphatic polyesters: great degradable polymers that cannot do everything. Biomacromolecules 2005;6:538-546.
49 Natarajan J, Madras G, Chatterjee K: Tailoring the degradation rate and release kinetics from poly (galactitol sebacate) by blending with chitosan, alginate or ethyl cellulose. Int J Biol Macromol 2016; doi: 10.1016/j.ijbiomac.2016.02.039.

50 Lyu S, Untereker D: Degradability of polymers for implantable biomedical devices. Int J Mol Sci 2009;10: 4033-4065.

51 Chen G, Sato T, Ushida T, Hirochika R, Shirasaki Y, Ochiai N, Tateishi T: The use of a novel PLGA fiber/ collagen composite web as a scaffold for engineering of articular cartilage tissue with adjustable thickness. J Biomed Mater Res A 2003;67:1170-1180.

52 Capulli AK, MacQueen LA, Sheehy SP, Parker KK: Fibrous scaffolds for building hearts and heart parts. Adv Drug Deliv Rev 2016;96:83-102.

53 Duan B, Hockaday LA, Kang KH, Butcher JT: 3d bioprinting of heterogeneous aortic valve conduits with alginate/gelatin hydrogels. J Biomed Mater Res A 2013; 101:1255-1264.
54 Agnew DE, Stevermer AK, Youngquist JT, Pfleger BF: Engineering Escherichia coli for production of $\mathrm{C}_{12}-\mathrm{C}_{14}$ polyhydroxyalkanoate from glucose. Metab Eng 2012; 14:705-713.

55 Parmaksiz M, Dogan A, Odabas S, Elcin AE, Elcin YM: Clinical applications of decellularized extracellular matrices for tissue engineering and regenerative medicine. Biomed Mater 2016;11:022003.

56 Dijkman PE, Driessen-Mol A, Frese L, Hoerstrup SP. Baaijens FP: Decellularized homologous tissue-engineered heart valves as off-the-shelf alternatives to xenoand homografts. Biomaterials 2012;33:4545-4554.

57 Jana S, Tranquillo RT, Lerman A: Cells for tissue engineering of cardiac valves. J Tissue Eng Regen Med 2015

58 Takahashi K, Yamanaka S: Induction of pluripotent stem cells from mouse embryonic and adult fibroblast cultures by defined factors. Cell 2006;126:663-676.

59 Simpson DL, Wehman B, Galat Y, Sharma S, Mishra R, Galat V, Kaushal S: Engineering patient-specific valves using stem cells generated from skin biopsy specimens. Ann Thorac Surg 2014;98:947-954. 